Chapter 8

\title{
Molecular Mechanisms Underlying Pluripotency
}

\author{
Erhard Bieberich and Guanghu Wang \\ Additional information is available at the end of the chapter \\ http://dx.doi.org/10.5772/55596
}

\section{Introduction}

Pluripotency and self renewal are the two primary characteristics of pluripotent stem cells (PSCs) [1]-[4]. Pluripotency refers to the capacity of a single cell to give rise to any cell type of an embryo or an adult animal [5],[6]. A mammalian organism is developed from a single fertilized egg, the zygote, in an extremely ordered and error-proof fashion [7]. The zygote and the subsequent 2 to 4 -cell stage blastomere are considered to be totipotent since they can give rise to the entire fetus, including the embryo and the extra embryonic tissue such as the placenta and the umbilical cord (Fig.1) [7]. As embryo development proceeds to 8-cell stage and beyond depending on the species, the cells in the blastomere gradually lose their totipotency. At about embryonic day 3.5 (E3.5) in mouse (about E5 in human) the blastomere compacts into a blastocyst in which two distinct cell populations reside. Cells in the outer layer of the blastocyst form the trophectoderm (TE) which eventually give rise to the extra embryonic tissue, trophoblast of the placenta, whereas cells in the inside of the blastocyst form the inner cell mass (ICM). The ICM then gives rise to additional two lineages of cells, the primitive endoderm (PrEn or hypoblast) and the primitive ectoderm (PrEc or epiblast) (Fig.1). The PrEn produces the secondary extra embryonic tissues, such as yolk sac, allantois and amnion, while the PrEc gives rise to all three germ layers of the embryo, namely the ectoderm, the mesoderm and the endoderm (Fig.1). Although the extra embryonic tissues are indispensible for mammalian embryonic development, it is the ICM derived PrEc (or epiblast) cells that form all the cells of an embryo and adult animal, thus these cells are defined as pluripotent [5],[8].

As the embryo implants into the uterus and development further commences to E5-E6.5 days in mouse, some of the post-implantation epiblast cells are found to maintain the capability of producing all derivatives of the three embryonic germ layers [1],[5]. The difference between cells derived from ICM of the pre-implantation blastocyst and those from post-plantation epiblast is that the ICM derived cells express stage-specific embryonic antigen 1 (SSEA1), give rise to all three embryonic germ layers, and most importantly, contribute to chimeric mouse 
and germ line transmission, while those from post-implantation epiblast do not express SSEA1 and do not contribute to chimeric mouse and germ line [1],[5],[9]-[11]. Thus the ICM derived cells are defined to be in a "naive (or ground, primordial)" state of pluripotency, and those from post-implantation epiblast are defined to be in a "primed (or refined)" state of pluripotency [1],[5],[12],[13]. Other in vivo sources of pluripotent cells include the germline cells extracted either from embryonic or adult male reproduction organs [5],[8] (Fig. 1).

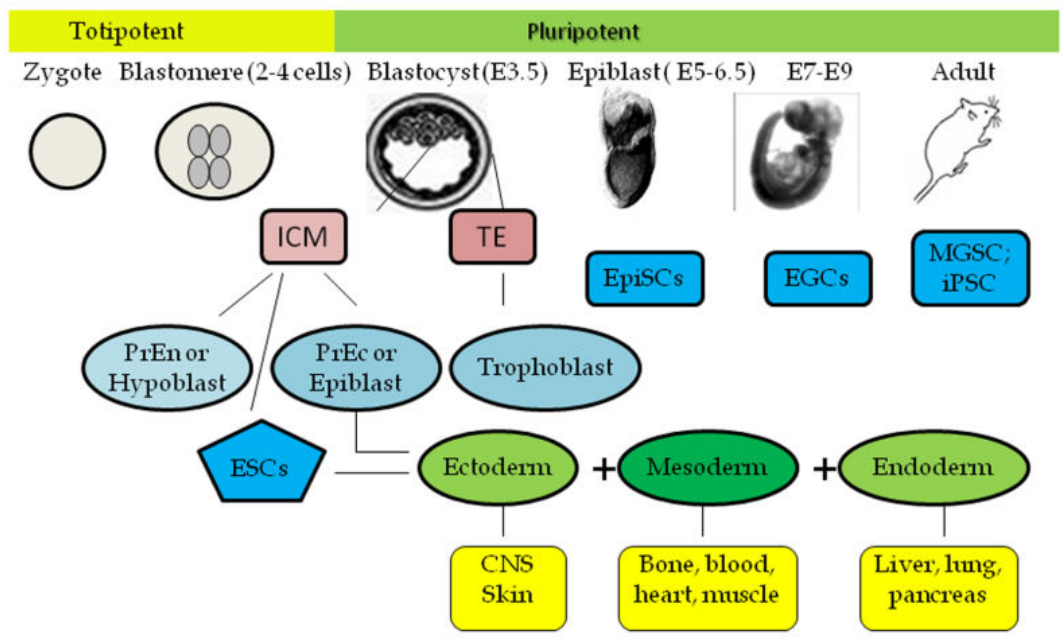

Figure 1. Early embryonic development and sources of PSCS. ICM, inner cell mass; TE, trophectoderm or Trophoblast; EpiSCs, epiblast stem cells; EGC, embryonic germ cells; iPSCs, induced pluripotent stem cells; MGSCs, male germ stem cells; PrEn, primitive endoderm; PrEc, primitive ectoderm; ESCs, embryonic stem cells.

Both the innate totipotency and pluripotency are transient developmental stages in the beginning of embryogenesis [5],[7]. Because of their finite number and transient nature, these cells are very challenging to study, although scientists have showed immense interest to understand them since they hold key answers to many aspects of biology and life.

Intriguingly, pluripotency can be captured or induced in cell cultures with defined growing conditions [14]-[16]. Mouse ESCs (mESCs) are one of the first and best-established ICMderived cells (Fig.1 and Table 1). Well defined culture conditions allow mESCs to self renew infinitely while maintaining a pluripotent state in vitro, providing an invaluable source of cells for molecular studies and differentiation into a variety of desired cell types (Table 1) [17]-[21].

Despite the genetic similarities between mouse and human, it was until two decades later that the first human ESCs (hESCs) were established in cell culture [9]. These cells give rise to all lineages of the primary germ layers and form teratomas (Table 1). Although they were also derived from ICM of pre-implantation embryos, the hESCs demonstrate many striking differences from mESCs (discussed in detail below). Since germ line transmission studies cannot be performed with these cells, it is not known at what exact pluripotency state the hESCs 
are. However, hESCs resemble more closely mouse epiblast stem cells (mEpiSCs), which were derived from post-implantation epiblast [16],[22], indicating that the hESCs are probably in a primed state of pluripotency (Table 1).

Decoding the molecular basis of pluripotency and self renewal is fundamental to the understanding of stem cell biology, embryonic development, and clinical application of regenerative medicine. The in vitro culture of these PSCs, especially those from induced pluripotent stem cells (iPSCs), has provided an unprecedented tool to investigate deeper into the molecular mechanism governing pluripotency. Gradually we have uncovered that pluripotency is regulated by a complex network of factors, including transcription factors and epigenetic regulators, which trigger multiple signaling transduction pathways, such as the TGF- $\beta$ pathway and Wnt pathway. Since the concise molecular mechanism controlling pluripotency varies among the different kinds of PSCs, we will first give a brief introduction of their properties.

\begin{tabular}{|c|c|c|c|c|c|c|}
\hline & mECCs & mESCs & miPSCs & mEpiSCs & hESCS & hiPSCs \\
\hline Origin & Teratoma & $\begin{array}{c}\text { ICM of } \\
\text { Blastocyst }\end{array}$ & Somatic cells & Late epiblast & ICM of Blastocyst & Somatic cells \\
\hline $\begin{array}{l}\text { Teratoma } \\
\text { formation }\end{array}$ & Yes & Yes & Yes & Yes & Yes & Yes \\
\hline $\begin{array}{l}\text { Chimera and } \\
\text { germ line } \\
\text { contribution }\end{array}$ & Yes & Yes & Yes & No & Not determined & $\begin{array}{c}\text { Not } \\
\text { determined }\end{array}$ \\
\hline $\begin{array}{l}\text { Culture } \\
\text { conditions }\end{array}$ & LIF, FBS & LIF, BMP4 & LIF & Fgf2, Activin & $\begin{array}{l}\text { Fgf2, Activin, } \\
\text { MEF CM }\end{array}$ & $\begin{array}{c}\text { Fgf2, Activin, } \\
\text { MEF CM }\end{array}$ \\
\hline Morphology & $\begin{array}{l}\text { Domed } \\
\text { shape }\end{array}$ & Domed shape & $\begin{array}{l}\text { Domed } \\
\text { shape }\end{array}$ & Flat & Flat & Flat \\
\hline $\begin{array}{c}\mathrm{X} \\
\text { chromosome }\end{array}$ & $\mathrm{XaXa}$ & $\mathrm{XaXa}$ & $\mathrm{XaXa}$ & XaXi & XaXi & $\mathrm{XaXi}$ \\
\hline $\begin{array}{c}\text { Pluripotency } \\
\text { status }\end{array}$ & & Naive state & & Primed state & $\begin{array}{r}\text { Not determined, } \\
\text { stat }\end{array}$ & ossibly primed \\
\hline $\begin{array}{l}\text { Pluripotency } \\
\text { factors }\end{array}$ & Oct4, N & og, Sox2, Stat3, & If2, Klf4, & & Oct4, Nanog, Sox2 & \\
\hline $\begin{array}{l}\text { Response to } \\
\text { LIF }\end{array}$ & \multicolumn{3}{|c|}{ Self renewal and pluripotency } & \multicolumn{3}{|c|}{ None } \\
\hline $\begin{array}{l}\text { Response to } \\
\text { Fgf2 }\end{array}$ & \multicolumn{3}{|c|}{ Differentiation } & \multicolumn{3}{|c|}{ Self renewal and pluripotency } \\
\hline $\begin{array}{c}\text { Response to } \\
2 \mathrm{i}\end{array}$ & \multicolumn{3}{|c|}{ Self renewal and pluripotency } & \multicolumn{3}{|c|}{ Differentiation and cell death } \\
\hline References & $7,17-19$ & $10-14,22-28$ & $32-35$ & $3,9,16$ & 4,15 & $51,53,54$ \\
\hline
\end{tabular}

Table 1. Properties of some PSCs 


\section{Properties of PSCs}

Mouse ECCs: Mouse embryonic carcinoma cells (mECCs), the first PSCs established in cell culture, were derived in 1964 from teratomas from an inbred mouse line, which produces spontaneous testicular teratomas (Table 1) [14],[23]. These cells show many aspects of naive PSCs, such as the expression of antigen SSEA1, differentiation into all three germ layers when stimulated, and generation of chimeric mice when injected into blastocysts [14],[23]-[25]. However, since the ECCs carry many mutations, the chimeric mice derived from these cells develop spontaneous tumors [26].

Mouse ESCs: Based on the findings made from mECCs, derivation of mESCs directly from ICM of normal developing embryos became possible and faster (Fig.1). Two groups, Kaufman's and Martin's, isolated such cells in culture from the ICM of pre-implantation blastocysts using different protocols in 1981 [15],[27]. And it was Martin who coined the term ESCs [27].

mESCs satisfy all the characteristics of naive pluripotency with a normal karyotype, resembling their in vivo counterparts in terms of expressing the pluripotency factors Oct4, Sox2, and Nanog, and SSEA1 and alkaline phosphatase (AP) (Table 1). They can be differentiated into all derivatives of the three germ layers; grow in a dome-shaped morphology; display a high nuclei/cytoplasm ratio; and most importantly, form teratomas and give rise to germ line transmission when injected into blastocysts (Table 1) [17]-[21].

The cell cycle control in mESCs also seems to be unique. They have an unusually short G1 phase and no regulation at the G1-S transition, the presence of hyperphosphorylated retinoblastoma (RB) protein, and unresponsiveness to activity of cyclin-dependent kinase 4 (CDK4) $[11],[28]$. Epigenetically, mESCs possess a hypermethylated genome and both X-chromosomes are activated if isolated from female embryos [29]-[31].

To grow mESCs, a feeder cell layer of mouse embryonic fibroblasts is typically used, with medium containing ES qualified fetal bovine serum or knockout serum replacement, leukemia inhibitory factor (LIF), non-essential amino acid, and $\beta$-mercaptoethanol [20],[21],[32],[33]. LIF serves as the extrinsic factor for pluripotency and self renewal by activating the signal transducer and activator of transcription 3 (Stat3) pathway [21],[34],[35]. Later it was discovered that LIF and Bone morphogenic protein 4 (BMP4) can support mESCs pluripotency without serum (Table 1) [36],[37]. More recently, it has been demonstrated that mESCs can be derived and maintained using medium containing small molecule inhibitors of glycogen synthase kinase (GSK3) (which functions to activate the Wnt signaling pathway) and the mitogen-activated protein kinase (MAPK) signaling pathways, completely devoid of serum and extrinsic growth factors [5],[38]. This culture media with defined components is termed the $2 \mathrm{i}$ (2 inhibitors) system [5],[38].

Mouse EpiSCs: Mouse Epiblast Stem cells (mEpiSCs) have been derived from post-implantation blastocysts (E5-E6.5) (Fig.1) [16],[22]. These cells demonstrate the properties of selfrenewal and pluripotency, but they cannot colonize the ICM of a blastocyst and produce germ line transmission [13],[16],[22]. Thus mEpiSCs are in the "primed" state of pluripotency. Furthermore, mEpiSCs express high levels of Oct4, Sox2, and Nanog but relatively low levels 
of other pluripotency factors that have been shown to be essential for mESCs, such as Klf4 and Stella [5],[13],[16]. This suggests fundamental differences in the mechanisms that maintain pluripotency in mESCs and mEpiSCs [8],[16].

Epigenetically, mEpiSCs display X chromosome inactivation (XCI) as well as stability of the genetic imprint [3],[5],[8]. This epigenetic status is shared with the late epiblast of the postimplantation embryo, which reinforces the similarity between cultured mEpiSCs and their in vivo counterpart. This similarity has been confirmed by gene expression profile experiments, which show that EpiSCs are closely related to the pluripotent cells located in the epiblast of a post-implantation embryo [16],[22]

Mouse EpiSCs also differ with mESCs regarding growing conditions, phenotypes and function. To keep them in a self renewing state, activin, fibroblast growth factor 2 (Fgf2), and transforming growth factor $\beta$ (TGF- $\beta$ ) are needed, whereas LIF is dispensable and BMP4 leads to differentiation (Table 1) [16],[22]. Instead of growing in a dome-shaped morphology as mESCs, mEpiSCs exhibit a flattened shape and do not propagate well as single cells. Whereas cell cycle regulation in mEpiSCs remains to be investigated in detail, the doubling time of mEpiSCs is 18 hours, compared with only 10-14 hours doubling time of mESCs, suggesting that a normal G1-S transition occurs in mEpiSCs [16],[22].

Human ESCs: Like mESCs, human ESCs (hESCs) were isolated from the ICM of the preimplantation blastocyst almost two decades after the isolation of mESCs [9]. hESCs possess the potential to differentiae into all three primary germ layers and to produce teratomas when injected into blastocysts [1],[9]. They express high levels of pluripotency factors Oct4, Nanog, and Sox2, and are positive for SSEA3/4 and AP. However, hESCs share multiple defining features with mouse EpiSCs rather than mESCs. These characteristics include flat morphology, dependence on FGF2/Activin signaling to self renew, inclination for $\mathrm{XCI}$, and reduced tolerance to single-cell dissociation by trypsinization (Table 1). These molecular and biological similarities with mEpiSCs suggest that hESCs correspond, at least partially, to the primed pluripotency state rather than to the naive state.

iPSCs: In 2006, Shinya Yamanaka's research group at Kyoto University made a milestone achievement by converting adult mouse cells back to a ground pluripotent stem cell-like state through exogenous expression of only four transcription factors, Oct4, Sox2, Klf4, and c-Myc [39]. These miPSCs exhibit all characteristics of mESCs, including expression of pluripotency marker protein, activation of both $\mathrm{X}$ chromosomes, and most importantly, the ability to generate chimeric animals and contributing to germ line transmission (Table 1). Later on, similar cells were also induced from human somatic cells. hiPSCs resemble more hESCs and mEpiSCs than mESCs (Table 1)[40]-[42]. As their production efficiency rapidly improved, iPSCs have soon been able to compete with traditional embryonic and adult stem cells [39][50]. The primary advantages of iPSCs compared to other stem cells are: a) iPSCs can be created from the tissue of the same patient that will receive the transplantation, thus avoiding immune rejection, and b) the lack of ethical implications because cells are harvested from a consent individual. These patient-specific cells can be used to study diseases in vitro, to test drugs on a human model without ethical concerns, and to hopefully be used as a source of tissue replacement for diseased and damaged cells. 


\section{Embryonic Germ stem Cells (mEGC) and Male Germ Stem Cell (MGSCs)}

PSCs have also been derived from reproductive system cells. When cultivated in adequate growth conditions, reproductive system cells generate ES-like stem cells (it is termed embryonic germ cells (EGCs) if isolated from mouse embryonic day 8.5 embryos [51], or male germ stem cells (MGSCs) if derived from postnatal male gonads [52]) (Fig.1). The EGCs and MGSCs are both naive stem cells, capable of generating all three embryonic germ layer cells, teratomas and chimeras. EGCs and MGSCs have also been derived from human sources, but their characteristics are not as well defined [53]-[55].

Next we will focus on the mESCs, which are in the naive state, and hESCs, which are probably in the primed state, to discuss the molecular mechanism of pluripotency maintenance.

\section{Transcription factors regulatating pluripotency}

An interplay of transcription factors and epigenetic factors participates in the maintenance of pluripotency of stem cells [34],[35],[56]-[62]. Among them Oct4 (or POU5F1), Nanog, and Sox2 are generally accepted as the core pluripotency factors, since they are vital to maintian the pluripotency of both the hESCs and mESCs, which are in a different pluripotency state [1],[8], [63]. These three factors also collectively bind to an array of genes that are essential for pluripotency and differentiation [1],[8],[63].

\subsection{Core pluripotency factors and their transcription cotrol}

The POU transcription factor Oct4 is a central player for stem cell pluripotency (Fig.2). Its expression is strictly confined to the totipotent, pluripotent, and germ cells during early development. In vitro, the cellular level of Oct4 must be tightly controlled to maintain the pluripotency status, up- or down-regulation by 50\% leads to ESC differentiation [64],[65]. In vivo, Oct4 deletion in mice leads to ICM failure [57].

The homeoprotein Nanog is another central factor for pluripotency (Fig.2) [66]. The ICM in Nanog-deficient mice fails to generate epiblast and only produces endoderm-like cells [66]. Furthermore, ESCs derived from Nanog-deficient mice cannot maintain pluripotency and instead differentiate into extraembryonic endoderm lineages [66]. Mechanistically, Nanog functions by inhibiting NF $\kappa B$ and cooperating with Stat3 to inhibit cell differentiation in mESCs [66]-[68].

The third central factor is Sox2 (Fig.2) [3],[5],[63],[69]. Sox2 exhibits an expression pattern similar to that of Oct4 during development [70]. Genetic ablation studies indicate that silencing of Sox2 affects a somewhat later stage of embryogenesis, possibly because of a stronger maternal contribution of Sox 2 protein. Key feature of acute Sox 2 loss appears to be an inability to sustain appropriate Oct4 levels [70]. 


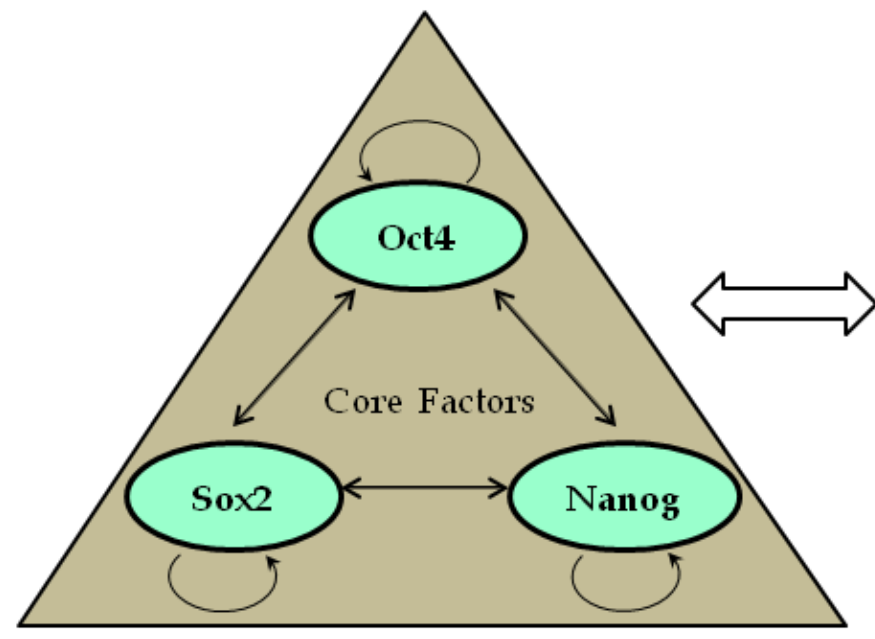

\begin{tabular}{|c|}
\hline KIF4 \\
cMyc \\
Stat3 \\
K1f2 \\
Sall4 \\
Dax1 \\
TCF4 \\
Sox18 \\
Zfp281
\end{tabular}

Figure 2. Schematic representation of the transcriptional regulation of core pluripotency factors and the extended factors

These three core factors do not function by themselves. Instead they are involved in a multiplegene complex to regulate stem cell pluripotency (Fig.2). Their interacting partners have been extensively studied by coimmunoprecipitation (Co-IP) or chromatin immunoprecipitation (ChIP) assays in both mESCs and hESCs. Oct4 has been found to associate with Sox2, Nanog, Smad1, Stat3, TCF3, Rest, Hsp90, etc. [4],[21],[71]-[73]. Nanog seems to interact with Oct4, Smad1, Nac1, Zfp281, and Hsp90 [21],[72]-[74]. And Sox2 associates with Oct4, Nanog, Klf4, Rpa1, Sall4, and Npm1 [75],[76].

One unique aspect of the regulation of these core factors is that they act together to regulate their own promoters, forming an interconnected auto-regulatory feedback loop (Fig.2) [5], [51], [71]. Another unique aspect is that they co-occupy and active/enhance expression of other genes necessary to maintain ESC status, while contributing to repression of genes encoding differentiation signals (Fig.2) [5],[51],[71],[77]-[80]. For example, binding of Oct4 to a promoter region of a gene increases the likelihood of Nanog, Sox2, and other regulatory factors to bind to the same promoter [5],[51],[71],[77]-[80].

Apart from transcriptional control of these core factors, post-translational modifications also play an essential role. Oct4 has been reported to be ubiquitinated in differentiating mouse embryonic carcinoma cells but not in mESCs [81],[82]. Phosphorylation of Nanog promotes its interaction with the prolyl isomerase Pin1, leading to increased Nanog stability by suppressing its ubiquitination[83]. In addition, a recent report demonstrates that Hsp90, a molecular chaperone, associates with Oct 4 and Nanog and maintains their cellular level, possibly through protecting them against degradation by the ubiquitin protesome pathway [21]. These studies demonstrate that post-translational modifications and protein stability of the pluripotency factors is also vital for stem cell pluripotency maintenance. 


\subsection{Extended network of regulatory factors}

Besides the core pluripotency factors, many other transcription factors participate in the regulation of stem cell pluripotency, including cMyc, Klf2, Klf4, Stat3, Rex1, Sall4, Zfp281, and the proteins associated with the three core factors [1],[3],[5]. These transcription factors participate in the pluripotency regulation in a state or species-specific fashion. For example, Stat3 plays an important role in mESC pluripotency since target deletion of Stat3 resulted in early embryonic lethality, and ectopic expression of a dominant-negative Stat3 in ESCs leads to loss of pluripotency [34],[35]. However, Stat3 is not suficient to maintain the pluripotency of hESCs and mEpiSCs [21],[84].

\section{Signal transduction pathways in pluripotency maintenance}

Innate signal transduction pathways are crucially important for understanding the regulation of the stem cell pluripotency. Extensive efforts, including high throughput genetic and chemical screening, have been invested into identifying genes and pathways that affect the core pluripotency factors Oct4, Nanog, and Sox2, or their associated genes. We have now gradually obtained a glimpse of the intrinsic signalling pathways that are involved in the regulation of stem cell pluripotency and differentiation. These signallng pathways include the Wnt pathway, TGF- $\beta$ pathway, LIF/Stat3 pathway, Fgf pathway, insulin geowth factor (IGF) pathway, Notch pathway, Hedgehog pathway, etc [3]-[5],[71],[74],[85],[86] (Fig.3). Among them, the Wnt and TGF- $\beta$ pathways are most heavily studied and best understood in terms of their roles in stem cell pluripotency maintenance. Here, we will focus on discussing the Wnt pathway, TGF- $\beta$ signaling, LIF/Stat3 pathway, and the Fgf pathway (Figs. 3 and 4).

\subsection{WNT signaling pathway}

The Wnt pathway plays an important role in tissue development by regulating a wide range of cellular processes such as proliferation, adhesion, morphology, and migration [87]-[91]. It consists of over 30 extracellular ligands that bind to Frizzled (FZD) and low-density lipoprotein receptor related protein (LRP) receptors at the cell surface (Fig.3) [91]. The Wnt ligands are able to activate both the canonical pathway and the non-canonical pathway [88],[92]. The activation of Wnt pathway in the canonical pathway results in the preservation of $\beta$-catenin and its subsequent nuclear translocation, which enables downstream gene activation by the TCF/LEF family transcription factors [87]-[95]. The non-canonical pathway is independent of $\beta$-catenin and involves the activation of several other signaling pathways, such as the JNK pathway [3]-[5],[88],[91],[92].

The Wnt signaling pathway is directly linked to the core transcriptional network of pluripotency and is demonstrated to be essential for self renewal and pluripotency of both naïve and primed PSCs, when LIF is absent. Evidences for this notion include: 1), Wnt signaling is activated in both mESCs and hESCs, and is down-regulated during differentiation [90]; 2), activation of the canonical Wnt pathway is required to maintain the expression level of core pluripotency factors Oct4 and Nanog, through which the self-renewal and pluripotency are 
sustained (Figs. 3 and 4); and 3), ectopic expressing of an constitutively active form of $\beta$-catenin maintains the expression levels of Oct4 and Nanog and thus self renewal and pluripotency in ESCs [96].

Moreover, Wnt signaling inhibits the differentiation of ESCs, especially to neural differentiation [90],[97],[98]. Mutation of Apc, an important mediator in the Wnt pathway, leads to impaired differentiation both in vitro and in teratomas [99]. Furthermore, ESCs with highly elevated $\beta$-catenin levels also have a compromised ability to differentiate [10].

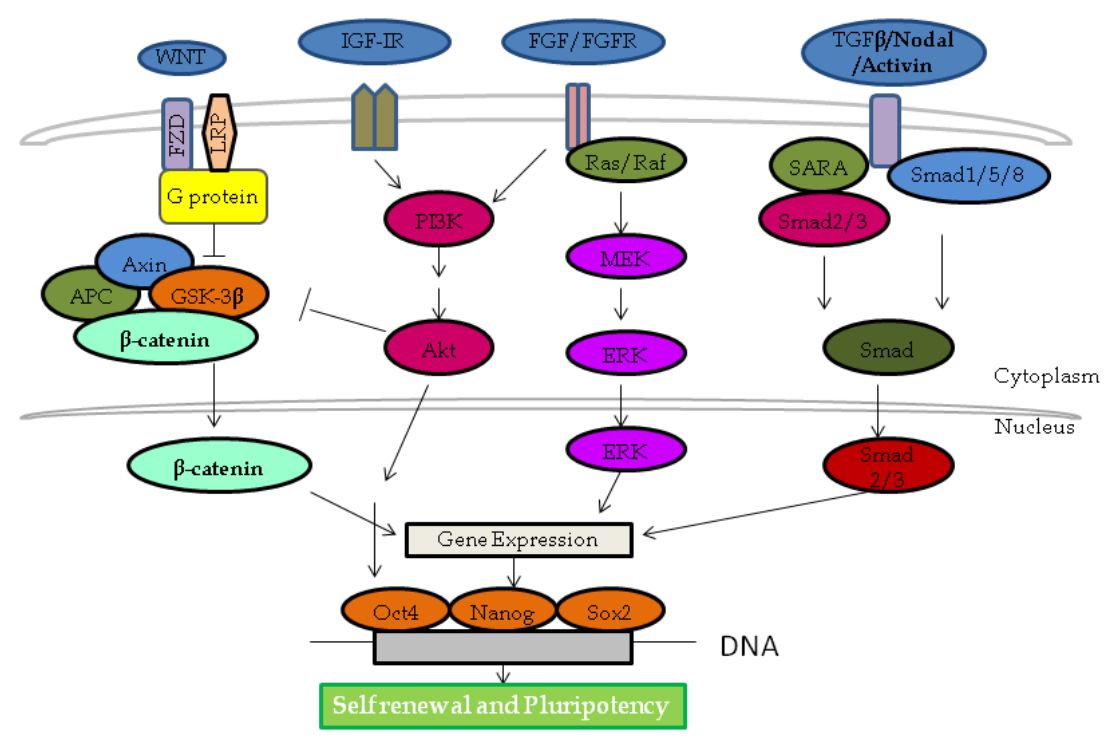

Figure 3. Signaling pathways regulating pluripotency of the primed stem cells, such as mEpiSCs and possibly hESCs

The role of the Wnt signaling in stem cell pluripotency is further confirmed by its down-stream effectors, the TCF/LEF family of transcription factors [72],[88],[92],[100],[101]. In ESCs, TCF3 is the most abundantly expressed member of this transcription factor family. TCF3-null ESCs have an increased resistance to differentiation and up-regulation of various Oct4 and Nanogregulated genes [74],[102],[103]. Activation of Wnt converts TCF3 into an activator, elevating the expression of these same targets and suppressing differentiation [103]. TCF3 may also suppress the expression of Oct4 and Nanog, although its ability to activate these targets is unclear [104],[105].

However, Wnt signaling alone is not sufficient to support the ground state pluripotency [38]. It has been shown that inhibition of GSK3 in mESCs enhances growth capacity and suppresses neural differentiation, but it also promotes non-neural differentiation [37], [38]. To block differentiation of mESCs, the combination of a GSK3 inhibitor and an FGF-Erk inhibitor (the 2i system) [5],[38] is necessary. 


\subsection{TGF- $\beta$ signaling pathway}

The TGF- $\beta$ signaling pathway plays a vital role in both the developmental and adult life of a mammalian organism by regulating many processes including apoptosis, proliferation, senescence, inflammation, cell fate, and tissue repair [94],[106],[107]. The TGF- $\beta$ super family contains more than 30 growth factors including TGF- $\beta \mathrm{s}$, BMPs, growth and differentiation factors (GDFs), Activin, and Nodal [2],[106],[108]. The canonical signaling cascade of TGF- $\beta$ pathway involves the ligands of the TGF- $\beta$ super family binding to cell surface receptors that activate the Smad proteins in the cytoplasm, which leads to their nuclear translocation and transcriptional activation of target genes [108]. The noncanonical TGF- $\beta$ signaling includes intracellular signaling pathways activated by TGF- $\beta$ family members that do not activate Smad proteins [108]. The TGF- $\beta$ pathway can also be regulated by other key signaling pathways such as Wnt signaling pathways.

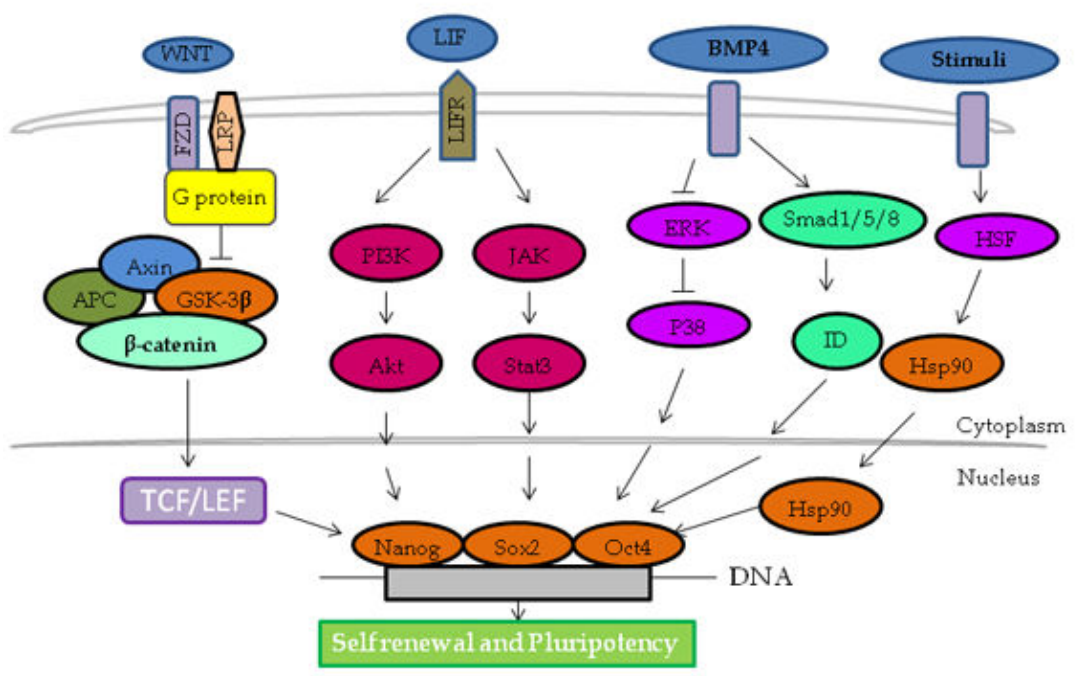

Figure 4. Signaling pathways regulating pluripotency of the naive stem cells, such as mESCs and miPSCs

All members of this family are important for stem cell pluripotency and self-renewal of both mESCs and hESCs, although the role of these signaling molecules appears to differ between the two types of cells [109]. In mESCs, BMP4 maintains self-renewal through inhibition of the MAPK/ERK pathway and the expression of Id protein [36],[37], and promotes mESC proliferation via an increase in Wnt expression (Fig.4) [86]. In contrast, BMP4 promotes hESC differentiation through down-regulation of Nanog and Oct4 [110]. Long-term maintenance of hESC pluripotency therefore requires down-regulation of BMP activity by Noggin and Fgf2 [85]. In hESCs, on the other hand, it is other members of the TGF- $\beta$ super family that maintain their pluripotency. Phosphorylation and nuclear localization of Smad 2 induced by TGF- $\beta$, Activin, or Nodal signaling was observed in undifferentiated hESCs and is decreased upon 
early differentiation (Fig.3) [111]. Activin A is demonstrated to be able to support long-term feeder-free culture and maintenance of pluripotency in hESCs by inducing the expression of Oct4 and Nanog, and suppressing BMP (Fig.3) [87]. Nodal expression also plays a role in the maintenance of human ES cell pluripotency through the inhibition of neuroectodermal differentiation, a default differentiation pathway of ESCs (Fig.3) [112]. Furthermore, inhibition of the TGF- $\beta$ /Activin/Nodal pathways initiated differentiation and resulted in the decreased expression of stem cell marker proteins [111],[113].

In addition, Activin and Nodal signaling has been shown to promote mESC self-renewal in serum-free conditions [114]. It is therefore clear that TGF- $\beta$ signaling plays an important role in the maintenance of self-renewal and pluripotency, although the exact mechanism of action for this family of growth factors appears to differ between family members, pluripotency state, and species (Figs. 3 and 4).

BMPs are also potent inhibitors of differentiation in mouse embryos. Knockdown of their down-stream mediator, Smad1 and Smad4, in mESCs leads to a change of the expression pattern of germ layer markers during differentiation [37],[115],[116]. TGF- $\beta$ signaling also participates in the cell fate decision making of mESCs. Multiple cell lineages, including neural, hematopoietic, cardiomyogenic, and hepatic, have been found to be affected by the TGF- $\beta$ family [115],[117]. For example, BMP4 regulates mesodermal cell commitment to the hematopoietic lineage and specifies blood lineages at the later stages of differentiation [118]-[120]. Another study found that BMP4 and Activin induce mesoderm differentiation into cardiac lineage [121]. In addition, BMP2-induced mesodermal and cardiac specification results in full cardiogenic differentiation, leading to an enrichment of cardiomyocytes within embryoid bodies [122]. This ability of the TGF- $\beta$ family members to commit mESCs toward a mesodermal fate is thought to be due to Smad-mediated regulation of the Oct4 promoter, further implicating a role for Smad signaling in the regulation of the core self-renewal network in ESCs [123], [124]. Consistent with this notion, it is found that several Smad target genes overlap with genes bound by the key pluripotency factors, for example, Smad4-regulated genes have a substantial overlap with those of Sox2, NR0B1/Dax1, and Klf4 [116]. In addition, another study demonstrated that several Smad targets were mapped to Nanog, Oct4, and TCF3-bound genes [116].

Jak/Stat3 pathway The self renewal and pluripotency of mESCs are initially maintained by an extrinsic factor, leukemia inhibitory factor (LIF) [7]. The key downstream mediators of LIF are the Jak/Stat pathway [7]. Stat3 has multiple roles in the regulation of mESC pluripotency including gene activation, cell cycle regulation, and inhibition of differentiation pathways [35], [125]. The activation of the Stat3 pathway by LIF induces transcription of self-renewal and pluripotency genes such as Nanog [35],[125]. Furthermore, constitutively active Stat3 promotes mESC self-renewal in the absence of LIF [35],[125]. Stat3 has also been reported to function through the regulation of c-Myc and Klf family proteins [126],[127], although these target genes have not been shown to be completely sufficient to replace the effect of LIF. This ability of LIF-mediated activation of Stat 3 to support the long-term self-renewal of mESCs in vitro has been supported in vivo by the requirement of this pathway in gp130-deficient blastocysts, an embryonic diapause case [128]. 
In addition to Stat 3 homodimers, Stat 1 is able to heterodimerize with Stat 3 in mESCs. However, Stat1 is unlikely to be required for self-renewal and pluripotency as LIF still maintains undifferentiated growth of Stat1-deficient cells [129].

Although it is sufficient to maintain the pluripotency of mESCs, the Jak/Stat3 pathway does not appear to maintain pluripotency of hESCs, which are possibly in the primed state of pluripotency [90], indicating that the signaling pathways responsible for maintaining pluripotency is species (or pluripotency state)-specific.

\subsection{Fgf and the MAPK pathway}

Fgf2 (or basic Fgf) is the first growth factor identified as being crucial for hESC pluripotency maintenance and self renewal. It is widely accepted that a serum-free culture of hESCs on mouse feeder cells requires soluble Fgf2 [88],[107],[130],[131]. In hESCs, exogenous Fgf2 activates the ERK/MAPK pathway, which is thought to be necessary for the maintenance of pluripotency, although the mechanism of action is still unclear [130],[132],[133]. In contrast to hESCs, mESCs and miPSCs do not require the Fgf2 or the ERK/MAPK pathway for pluripotency and self-renewal (Table 1) [5],[11]. Actually, ERK signaling triggers mESCs to differentiate towards the primitive endoderm lineage (Table 1) [1],[134]. Interestingly, inhibition of ERK activity has been shown to enhance the efficiency of mESC derivation from mouse embryos [135]. The mechanism underlying this seems to be that ERK1/2 activation triggers mESCs to exit the self-renewal program and enter lineage differentiation [136]. As mentioned earlier, the direct consequence of this is that blocking the ERK/MAPK-mediated differentiation pathway can help the derivation and maintenance of naive state PSCs, such as mESCs.

\section{Epigenetic factors regulating stem cell pluripotency}

Apart from the aforementioned transcription factors, epigenetics factors have also been found to play a vital role in stem cell pluripotency. These mechanisms include covalent modification of histone, DNA methylation and acetylation, and non-coding RNAs [31],[62],[137],[138]. Here we will discuss the functions of noncoding RNAs and chromatin remodeling factors in stem cell pluripotency.

\subsection{Noncoding RNAs}

The best understood class of noncoding RNA is the family of microRNAs (miRNAs), short RNAs capable of destabilizing and repressing specific target RNAs. These miRNAs are generally generated by the enzymes Dicer and Dcgr8 [139]-[141]. As for their function in stem cell pluripotency, it has been shown that genetic ablation of these enzymes affects the cell cycle and differentiation of ESCs [139]-[141]. Furthermore, some specific miRNAs are involved in pluripotency regulation. For example, mir-302 and mir-290-295 bind directly to and modulate the core pluripotency factors Oct4, Sox2, and Nanog [6]. miR-145 represses the 3' untranslated regions of Oct4, Sox2, and Klf4, thus increasing the amount of mir-145 leads to loss of pluripotency [142]. It is further demonstrated that Oct4 also binds to the promoter of mir-145 and 
suppresses its expression, forming a negative feedback loop involving mir-145, Oct4, Nanog, and Klf4 [142].

Another very important member of the miRNA family is let7 which has differentiation promoting activities itself, and also targets some of the pluripotency-associated genes [143], [144]. Let7 expression is negatively regulated by the RNA binding protein Lin28 [145]. Upon differentiation of pluripotent cells, Lin28 is down-regulated, resulting in stabilization and increase in the level of let7 [146]. This in turn provides the basis for establishment of negative feedback loops in which let7 expression is negatively regulated by the RNA binding protein Lin28 [145].

Recently, Oct4 has been shown to control and activate the expression of another type of noncoding RNA, the large intergenic noncoding RNAs [147]. Interestingly, knockdown of the expression of such RNAs caused growth defects and apoptosis, implying that these noncoding RNAs are involved in self-renewal and reprogramming of stem cells [147],[148].

\subsection{Chromatin remodeling factors}

Chromatin remodeling factors are recruited to the DNA to modify the density of the nucleosomes, thereby affecting gene expression [149],[150]. Some of these factors are essential for PSC viability, stability, and differentiation [31],[151],[152]. The ones known to have the most profound impact on ESC pluripotency are histone-modifying enzymes, such as Polycomb group (PcG) protein complexes, SetDB1, and Tip60-p400 [153],[154]. These enzymes repress genes that encode lineage-specific differentiation regulators by catalyzing methylation or ubiquitination of the histones in their promoters [153]-[155].

It is demonstrated that sumoylated SetDB1 binds to Oct4 and represses its expression [153], [156]. Loss of the Tip60-p400 complex affects ESC morphology and state [154]. The Tip60-p400 complex is shown to associate with active promoters in ESCs and appears to be recruited directly by the H3K4me3 mark and indirectly by Nanog [154]. Interestingly, the complex is also associated with nucleosomes with $\mathrm{H} 3 \mathrm{~K} 4 \mathrm{me} 3$ at PcG-occupied genes encoding lineage specific regulators, where it apparently facilitates repression of these poised genes [154].

\section{Conclusion}

Our understanding of the nature of pluripotency has been formulated extensively by the recent development of different lines of PSCs, especially the iPSCs. Although differences exist between them, the naïve and primed PSCs share certain similarities. For example, they both express the core pluripotency factors, Oct4, Nanog, and Sox2. The core transcription factors frequently share enhancers and autoregulate themselves. They also collectively bind to the promoters of an expanded network of proteins, including pluripotencyassociated factors and lineage-specific factors, to enhance or repress their gene expression, through which the fate of the cells is determined. The epigenetic studies have added another layer of complexity of the regulation of these core pluripotency factors and hence 
pluripotency. In addition, a recent study of our/my laboratory shows that Hsp90 maintains stem cell pluripotency by associating with and sustaining the cellular levels of Oct4 and Nanog, implying that the maturation or stability of these core pluripotency factors are crucially important for stem cell pluripotency [21].

Many of the methodologies to induce or convert somatic cells into PSCs involve using chemical inhibitors targeting specific pathways. This highlights the importance of understanding the roles of signaling pathways in stem cell pluripotency and self-renewal.

Furthermore, an in-depth understanding of pluripotency is highly applicable to regenerative medicine. Knowledge of their culture condition, state of pluripotency, and signal transduction pathways could greatly facilitate in vitro culture, manipulation, and differentiation, either from autologous or allogeneic sources. This knowledge will also guide a more effective generation of iPSCs, which will ultimately lead to individualized regenerative medicine.

\section{Acknowledgements}

This work is supported by a grant from American Heart Association and an intramural grant from Georgia Health Sciences University to GW, and in part by NIH (R01AG034389) and NSF (1121579) to EB. We are also thankful for the support by the Institute of Molecular Medicine and Genetics (under the directorship of Dr. Lin Mei) of Genetics of Georgia Health Sciences University (soon to be Georgia Regents University Augusta).

\section{Author details}

Erhard Bieberich and Guanghu Wang*

*Address all correspondence to: gwang@gru.edu

Institute of Molecular Medicine and Genetics, Medical College of Georgia, Georgia Regents University, Augusta, GA, USA

\section{References}

[1] Young, R. A. Control of the embryonic stem cell state. Cell 144, 940-954, doi:S0092-8674(11)00071-7 [pii]10.1016/j.cell.2011.01.032 (2011).

[2] Tiedemann, H., Asashima, M., Grunz, H. \& Knochel, W. Pluripotent cells (stem cells) and their determination and differentiation in early vertebrate embryogenesis. Dev Growth Differ 43, 469-502, doi:dgd599 [pii] (2001). 
[3] Xue, K., Ng, J. H. \& Ng, H. H. Mapping the networks for pluripotency. Philos Trans $R$ Soc Lond B Biol Sci 366, 2238-2246, doi:366/1575/2238 [pii]10.1098/rstb.2011.0005 (2011).

[4] Greenow, K. \& Clarke, A. R. Controlling the stem cell compartment and regeneration in vivo: the role of pluripotency pathways. Physiol Rev 92, 75-99, doi:92/1/75 [pii]10.1152/physrev.00040.2010 (2012).

[5] Dejosez, M. \& Zwaka, T. P. Pluripotency and nuclear reprogramming. Annu Rev Biochem 81, 737-765, doi:10.1146/annurev-biochem-052709-104948 (2012).

[6] Marson, A. et al. Connecting microRNA genes to the core transcriptional regulatory circuitry of embryonic stem cells. Cell 134, 521-533, doi:S0092-8674(08)00938-0 [pii]10.1016/j.cell.2008.07.020 (2008).

[7] Mitalipov, S. \& Wolf, D. Totipotency, pluripotency and nuclear reprogramming. Adv Biochem Eng Biotechnol 114, 185-199, doi:10.1007/10_2008_45 (2009).

[8] Pauklin, S., Pedersen, R. A. \& Vallier, L. Mouse pluripotent stem cells at a glance. J Cell Sci 124, 3727-3732, doi:124/22/3727 [pii]10.1242/jcs.074120 (2011).

[9] Thomson, J. A. et al. Embryonic stem cell lines derived from human blastocysts. Science 282, 1145-1147 (1998).

[10] Vescovi, A. L., Reynolds, B. A., Rietze, R. L. \& Bjornson, C. Ground-breaking stemcell work has been reproduced. Nature 447, 259 (2007).

[11] Burdon, T., Smith, A. \& Savatier, P. Signalling, cell cycle and pluripotency in embryonic stem cells. Trends Cell Biol 12, 432-438, doi:S0962892402023528 [pii] (2002).

[12] Krishnamurthy, K., Wang, G., Silva, J., Condie, B. G. \& Bieberich, E. Ceramide regulates atypical PKCzeta/lambda-mediated cell polarity in primitive ectoderm cells. A novel function of sphingolipids in morphogenesis. J Biol Chem 282, 3379-3390, doi:M607779200 [pii]10.1074/jbc.M607779200 (2007).

[13] Nichols, J. \& Smith, A. Naive and primed pluripotent states. Cell Stem Cell 4, 487-492, doi:S1934-5909(09)00224-0 [pii]10.1016/j.stem.2009.05.015 (2009).

[14] Evans, M. Discovering pluripotency: 30 years of mouse embryonic stem cells. Nat Rev Mol Cell Biol 12, 680-686, doi:nrm3190 [pii]10.1038/nrm3190 (2011).

[15] Evans, M. J. \& Kaufman, M. H. Establishment in culture of pluripotential cells from mouse embryos. Nature 292, 154-156 (1981).

[16] Tesar, P. J. et al. New cell lines from mouse epiblast share defining features with human embryonic stem cells. Nature 448, 196-199, doi:nature05972 [pii]10.1038/ nature05972 (2007). 
[17] Kuijk, E. W., Chuva de Sousa Lopes, S. M., Geijsen, N., Macklon, N. \& Roelen, B. A. The different shades of mammalian pluripotent stem cells. Hum Reprod Update 17, 254-271, doi:dmq035 [pii]10.1093/humupd/dmq035 (2011).

[18] Ginis, I. et al. Differences between human and mouse embryonic stem cells. Dev Biol 269, 360-380, doi:10.1016/j.ydbio.2003.12.034S0012160604000193 [pii] (2004).

[19] Singh, S. K., Kagalwala, M. N., Parker-Thornburg, J., Adams, H. \& Majumder, S. REST maintains self-renewal and pluripotency of embryonic stem cells. Nature 453, 223-227, doi:nature06863 [pii]10.1038/nature06863 (2008).

[20] Bieberich, E., Silva, J., Wang, G., Krishnamurthy, K. \& Condie, B. G. Selective apoptosis of pluripotent mouse and human stem cells by novel ceramide analogues prevents teratoma formation and enriches for neural precursors in ES cell-derived neural transplants. J Cell Biol 167, 723-734 (2004).

[21] Bradley, E., Bieberich, E., Mivechi, N. F., Tangpisuthipongsa, D. \& Wang, G. Regulation of embryonic stem cell pluripotency by heat shock protein 90. Stem Cells 30, 1624-1633, doi:10.1002/stem.1143 (2012).

[22] Brons, I. G. et al. Derivation of pluripotent epiblast stem cells from mammalian embryos. Nature 448, 191-195, doi:nature05950 [pii]10.1038/nature05950 (2007).

[23] Kleinsmith, L. J. \& Pierce, G. B., Jr. Multipotentiality of Single Embryonal Carcinoma Cells. Cancer Res 24, 1544-1551 (1964).

[24] Gooi, H. C. et al. Stage-specific embryonic antigen involves alpha 1 goes to 3 fucosylated type 2 blood group chains. Nature 292, 156-158 (1981).

[25] Solter, D. \& Knowles, B. B. Monoclonal antibody defining a stage-specific mouse embryonic antigen (SSEA-1). Proc Natl Acad Sci U S A 75, 5565-5569 (1978).

[26] Papaioannou, V. E., McBurney, M. W., Gardner, R. L. \& Evans, M. J. Fate of teratocarcinoma cells injected into early mouse embryos. Nature 258, 70-73 (1975).

[27] Martin, G. R. Isolation of a pluripotent cell line from early mouse embryos cultured in medium conditioned by teratocarcinoma stem cells. Proc Natl Acad Sci U S A 78, 7634-7638 (1981).

[28] Savatier, P., Lapillonne, H., van Grunsven, L. A., Rudkin, B. B. \& Samarut, J. Withdrawal of differentiation inhibitory activity/leukemia inhibitory factor up-regulates D-type cyclins and cyclin-dependent kinase inhibitors in mouse embryonic stem cells. Oncogene 12, 309-322 (1996).

[29] Minkovsky, A., Patel, S. \& Plath, K. Concise review: Pluripotency and the transcriptional inactivation of the female Mammalian X chromosome. Stem Cells 30, 48-54, doi: 10.1002/stem.755 (2012).

[30] Bernstein, B. E., Meissner, A. \& Lander, E. S. The mammalian epigenome. Cell 128, 669-681, doi:S0092-8674(07)00128-6 [pii]10.1016/j.cell.2007.01.033 (2007). 
[31] Meissner, A. Epigenetic modifications in pluripotent and differentiated cells. Nat Biotechnol 28, 1079-1088, doi:nbt.1684 [pii]10.1038/nbt.1684 (2010).

[32] Wang, G. et al. Direct binding to ceramide activates protein kinase Czeta before the formation of a pro-apoptotic complex with PAR-4 in differentiating stem cells. J Biol Chem 280, 26415-26424 (2005).

[33] Bieberich, E., MacKinnon, S., Silva, J., Noggle, S. \& Condie, B. G. Regulation of cell death in mitotic neural progenitor cells by asymmetric distribution of prostate apoptosis response 4 (PAR-4) and simultaneous elevation of endogenous ceramide. J Cell Biol 162, 469-479 (2003).

[34] Raz, R., Lee, C. K., Cannizzaro, L. A., d'Eustachio, P. \& Levy, D. E. Essential role of STAT3 for embryonic stem cell pluripotency. Proc Natl Acad Sci U S A 96, 2846-2851 (1999).

[35] Niwa, H., Burdon, T., Chambers, I. \& Smith, A. Self-renewal of pluripotent embryonic stem cells is mediated via activation of STAT3. Genes Dev 12, 2048-2060 (1998).

[36] Qi, X. et al. BMP4 supports self-renewal of embryonic stem cells by inhibiting mitogen-activated protein kinase pathways. Proc Natl Acad Sci U S A 101, 6027-6032, doi: 10.1073/pnas.04013671010401367101 [pii] (2004).

[37] Ying, Q. L., Nichols, J., Chambers, I. \& Smith, A. BMP induction of Id proteins suppresses differentiation and sustains embryonic stem cell self-renewal in collaboration with STAT3. Cell 115, 281-292, doi:S009286740300847X [pii] (2003).

[38] Ying, Q. L. et al. The ground state of embryonic stem cell self-renewal. Nature 453, 519-523, doi:nature06968 [pii]10.1038/nature06968 (2008).

[39] Takahashi, K. \& Yamanaka, S. Induction of pluripotent stem cells from mouse embryonic and adult fibroblast cultures by defined factors. Cell 126, 663-676, doi:S0092-8674(06)00976-7 [pii]10.1016/j.cell.2006.07.024 (2006).

[40] Takahashi, K. et al. Induction of pluripotent stem cells from adult human fibroblasts by defined factors. Cell 131, 861-872, doi:S0092-8674(07)01471-7 [pii]10.1016/j.cell. 2007.11.019 (2007).

[41] Takahashi, K., Okita, K., Nakagawa, M. \& Yamanaka, S. Induction of pluripotent stem cells from fibroblast cultures. Nat Protoc 2, 3081-3089, doi:nprot.2007.418 [pii]10.1038/nprot.2007.418 (2007).

[42] Yamanaka, S. Induction of pluripotent stem cells from mouse fibroblasts by four transcription factors. Cell Prolif 41 Suppl 1, 51-56, doi:CPR493 [pii]10.1111/j. 1365-2184.2008.00493.x (2008).

[43] Cheng, D., Lei, L., Lu, Z., Li, Z. \& Wang, H. [Induction and characterization of induced pluripotent stem (iPS) cells: a review]. Sheng Wu Gong Cheng Xue Bao 26, 421-430 (2010). 
[44] Huangfu, D. et al. Induction of pluripotent stem cells by defined factors is greatly improved by small-molecule compounds. Nat Biotechnol 26, 795-797, doi:nbt1418 [pii]10.1038/nbt1418 (2008).

[45] Cho, H. J. et al. Induction of pluripotent stem cells from adult somatic cells by protein-based reprogramming without genetic manipulation. Blood 116, 386-395, doi:blood-2010-02-269589 [pii]10.1182/blood-2010-02-269589 (2010).

[46] Hjelm, B. E. et al. Induction of pluripotent stem cells from autopsy donor-derived somatic cells. Neurosci Lett 502, 219-224, doi:S0304-3940(11)01125-6 [pii]10.1016/j.neulet. 2011.07.048 (2011).

[47] Okahara-Narita, J. et al. Induction of pluripotent stem cells from fetal and adult cynomolgus monkey fibroblasts using four human transcription factors. Primates, doi: 10.1007/s10329-011-0283-1 (2011).

[48] Oda, Y. et al. Induction of pluripotent stem cells from human third molar mesenchymal stromal cells. J Biol Chem 285, 29270-29278, doi:M109.055889 [pii]10.1074/ jbc.M109.055889 (2010).

[49] Shi, Y. et al. Induction of pluripotent stem cells from mouse embryonic fibroblasts by Oct4 and Klf4 with small-molecule compounds. Cell Stem Cell 3, 568-574, doi:S1934-5909(08)00527-4 [pii] 10.1016/j.stem.2008.10.004 (2008).

[50] Huangfu, D. et al. Induction of pluripotent stem cells from primary human fibroblasts with only Oct4 and Sox2. Nat Biotechnol 26, 1269-1275, doi:nbt.1502 [pii]10.1038/nbt.1502 (2008).

[51] Surani, M. A. Reprogramming a somatic nucleus by trans-modification activity in germ cells. Semin Cell Dev Biol 10, 273-277, doi:10.1006/scdb. 1998.0285S1084-9521(98)90285-3 [pii] (1999).

[52] Kanatsu-Shinohara, M. et al. Generation of pluripotent stem cells from neonatal mouse testis. Cell 119, 1001-1012, doi:S0092867404010578 [pii]10.1016/j.cell. 2004.11.011 (2004).

[53] Shamblott, M. J. et al. Derivation of pluripotent stem cells from cultured human primordial germ cells. Proc Natl Acad Sci U S A 95, 13726-13731 (1998).

[54] Conrad, S. et al. Generation of pluripotent stem cells from adult human testis. Nature 456, 344-349, doi:nature07404 [pii]10.1038/nature07404 (2008).

[55] Ko, K. et al. Human adult germline stem cells in question. Nature 465, E1; discussion E3, doi:nature09089 [pii]10.1038/nature09089 (2010).

[56] Mountford, P., Nichols, J., Zevnik, B., O'Brien, C. \& Smith, A. Maintenance of pluripotential embryonic stem cells by stem cell selection. Reprod Fertil Dev 10, 527-533 (1998). 
[57] Nichols, J. et al. Formation of pluripotent stem cells in the mammalian embryo depends on the POU transcription factor Oct4. Cell 95, 379-391, doi:S0092-8674(00)81769-9 [pii] (1998).

[58] Kim, J. B. et al. Oct4-induced pluripotency in adult neural stem cells. Cell 136, 411-419, doi:S0092-8674(09)00071-3 [pii]10.1016/j.cell.2009.01.023 (2009).

[59] Torres, J. \& Watt, F. M. Nanog maintains pluripotency of mouse embryonic stem cells by inhibiting NFkappaB and cooperating with Stat3. Nat Cell Biol 10, 194-201, doi:ncb1680 [pii]10.1038/ncb1680 (2008).

[60] Ebert, A. D. et al. Induced pluripotent stem cells from a spinal muscular atrophy patient. Nature 457, 277-280, doi:nature07677 [pii]10.1038/nature07677 (2009).

[61] Yu, J. et al. Human induced pluripotent stem cells free of vector and transgene sequences. Science 324, 797-801, doi:1172482 [pii]10.1126/science.1172482 (2009).

[62] Gan, Q., Yoshida, T., McDonald, O. G. \& Owens, G. K. Concise review: epigenetic mechanisms contribute to pluripotency and cell lineage determination of embryonic stem cells. Stem Cells 25, 2-9, doi:2006-0383 [pii]10.1634/stemcells.2006-0383 (2007).

[63] Hanna, J. H., Saha, K. \& Jaenisch, R. Pluripotency and cellular reprogramming: facts, hypotheses, unresolved issues. Cell 143, 508-525, doi:S0092-8674(10)01144-X [pii]10.1016/j.cell.2010.10.008 (2010).

[64] Niwa, H., Miyazaki, J. \& Smith, A. G. Quantitative expression of Oct-3/4 defines differentiation, dedifferentiation or self-renewal of ES cells. Nat Genet 24, 372-376, doi: $10.1038 / 74199$ (2000).

[65] Shimozaki, K., Nakashima, K., Niwa, H. \& Taga, T. Involvement of Oct3/4 in the enhancement of neuronal differentiation of ES cells in neurogenesis-inducing cultures. Development 130, 2505-2512 (2003).

[66] Mitsui, K. et al. The homeoprotein Nanog is required for maintenance of pluripotency in mouse epiblast and ES cells. Cell 113, 631-642, doi:S0092867403003933 [pii] (2003).

[67] Chambers, I. et al. Functional expression cloning of Nanog, a pluripotency sustaining factor in embryonic stem cells. Cell 113, 643-655, doi:S0092867403003921 [pii] (2003).

[68] Suzuki, A. et al. Nanog binds to Smad1 and blocks bone morphogenetic protein-induced differentiation of embryonic stem cells. Proc Natl Acad Sci U S A 103, 10294-10299, doi:0506945103 [pii]10.1073/pnas.0506945103 (2006).

[69] Avilion, A. A. et al. Multipotent cell lineages in early mouse development depend on SOX2 function. Genes Dev 17, 126-140, doi:10.1101/gad.224503 (2003).

[70] Masui, S. et al. Pluripotency governed by Sox 2 via regulation of Oct3/4 expression in mouse embryonic stem cells. Nat Cell Biol 9, 625-635, doi:ncb1589 [pii]10.1038/ ncb1589 (2007). 
[71] Chen, X. et al. Integration of external signaling pathways with the core transcriptional network in embryonic stem cells. Cell 133, 1106-1117, doi:S0092-8674(08)00617-X [pii]10.1016/j.cell.2008.04.043 (2008).

[72] van den Berg, D. L. et al. An Oct4-centered protein interaction network in embryonic stem cells. Cell Stem Cell 6, 369-381, doi:S1934-5909(10)00091-3 [pii]10.1016/j.stem. 2010.02.014 (2010).

[73] Liang, J. et al. Nanog and Oct4 associate with unique transcriptional repression complexes in embryonic stem cells. Nat Cell Biol 10, 731-739, doi:ncb1736 [pii]10.1038/ ncb1736 (2008).

[74] Boyer, L. A. et al. Core transcriptional regulatory circuitry in human embryonic stem cells. Cell 122, 947-956, doi:S0092-8674(05)00825-1 [pii]10.1016/j.cell.2005.08.020 (2005).

[75] Johansson, H. \& Simonsson, S. Core transcription factors, Oct4, Sox2 and Nanog, individually form complexes with nucleophosmin (Npm1) to control embryonic stem (ES) cell fate determination. Aging (Albany NY) 2, 815-822, doi:100222 [pii] (2010).

[76] Gao, Z. et al. Determination of protein interactome of transcription factor sox 2 in embryonic stem cells engineered for inducible expression of four reprogramming factors. J Biol Chem 287, 11384-11397, doi:M111.320143 [pii]10.1074/jbc.M111.320143 (2012).

[77] Ng, H. H. \& Surani, M. A. The transcriptional and signalling networks of pluripotency. Nat Cell Biol 13, 490-496, doi:ncb0511-490 [pii]10.1038/ncb0511-490 (2011).

[78] Loh, Y. H. et al. The Oct4 and Nanog transcription network regulates pluripotency in mouse embryonic stem cells. Nat Genet 38, 431-440, doi:ng1760 [pii]10.1038/ng1760 (2006).

[79] Boyer, L. A. et al. Polycomb complexes repress developmental regulators in murine embryonic stem cells. Nature 441, 349-353, doi:nature04733 [pii]10.1038/nature04733 (2006).

[80] Lee, T. I. et al. Control of developmental regulators by Polycomb in human embryonic stem cells. Cell 125, 301-313, doi:S0092-8674(06)00384-9 [pii]10.1016/j.cell. 2006.02.043 (2006).

[81] Liao, B. \& Jin, Y. Wwp2 mediates Oct4 ubiquitination and its own auto-ubiquitination in a dosage-dependent manner. Cell Res 20, 332-344, doi:cr2009136 [pii]10.1038/cr.2009.136 (2010).

[82] Li, H. et al. Wwp2-mediated ubiquitination of the RNA polymerase II large subunit in mouse embryonic pluripotent stem cells. Mol Cell Biol 27, 5296-5305, doi:MCB. 01667-06 [pii]10.1128/MCB.01667-06 (2007). 
[83] Moretto-Zita, M. et al. Phosphorylation stabilizes Nanog by promoting its interaction with Pin1. Proc Natl Acad Sci U S A 107, 13312-13317, doi:1005847107 [pii]10.1073/ pnas.1005847107 (2010).

[84] Daheron, L. et al. LIF/STAT3 signaling fails to maintain self-renewal of human embryonic stem cells. Stem Cells 22, 770-778, doi:10.1634/stemcells.22-5-770 22/5/770 [pii] (2004).

[85] Xu, R. H. et al. Basic FGF and suppression of BMP signaling sustain undifferentiated proliferation of human ES cells. Nat Methods 2, 185-190, doi:nmeth744 [pii] 10.1038/ nmeth744 (2005).

[86] Lee, M. Y., Lim, H. W., Lee, S. H. \& Han, H. J. Smad, PI3K/Akt, and Wnt-dependent signaling pathways are involved in BMP-4-induced ESC self-renewal. Stem Cells 27, 1858-1868, doi:10.1002/stem.124 (2009).

[87] Xiao, L., Yuan, X. \& Sharkis, S. J. Activin A maintains self-renewal and regulates fibroblast growth factor, Wnt, and bone morphogenic protein pathways in human embryonic stem cells. Stem Cells 24, 1476-1486, doi:2005-0299 [pii] 10.1634/stemcells. 2005-0299 (2006).

[88] Ding, V. M. et al. FGF-2 modulates Wnt signaling in undifferentiated hESC and iPS cells through activated PI3-K/GSK3beta signaling. J Cell Physiol 225, 417-428, doi: 10.1002/jcp.22214 (2010).

[89] Kim, L. \& Kimmel, A. R. GSK3 at the edge: regulation of developmental specification and cell polarization. Curr Drug Targets 7, 1411-1419 (2006).

[90] Sato, N., Meijer, L., Skaltsounis, L., Greengard, P. \& Brivanlou, A. H. Maintenance of pluripotency in human and mouse embryonic stem cells through activation of Wnt signaling by a pharmacological GSK-3-specific inhibitor. Nat Med 10, 55-63, doi: 10.1038/nm979 nm979 [pii] (2004).

[91] Bejsovec, A. Wnt pathway activation: new relations and locations. Cell 120, 11-14, doi:S0092867404012462 [pii] 10.1016/j.cell.2004.12.021 (2005).

[92] Widelitz, R. Wnt signaling through canonical and non-canonical pathways: recent progress. Growth Factors 23, 111-116, doi:T416183G77101V73 [pii] 10.1080/08977190500125746 (2005).

[93] Woodgett, J. R. Judging a protein by more than its name: GSK-3. Sci STKE 2001, RE12 (2001).

[94] Huang, J. et al. More synergetic cooperation of Yamanaka factors in induced pluripotent stem cells than in embryonic stem cells. Cell Res 19, 1127-1138, doi:cr2009106 [pii] 10.1038/cr.2009.106 (2009).

[95] Polakis, P. The oncogenic activation of beta-catenin. Curr Opin Genet Dev 9, 15-21 (1999). 
[96] Takao, Y., Yokota, T. \& Koide, H. Beta-catenin up-regulates Nanog expression through interaction with Oct-3/4 in embryonic stem cells. Biochem Biophys Res Commun 353, 699-705, doi:S0006-291X(06)02748-3 [pii] 10.1016/j.bbrc.2006.12.072 (2007).

[97] Haegele, L. et al. Wnt signalling inhibits neural differentiation of embryonic stem cells by controlling bone morphogenetic protein expression. Mol Cell Neurosci 24, 696-708, doi:S104474310300232X [pii] (2003).

[98] Aubert, J., Dunstan, H., Chambers, I. \& Smith, A. Functional gene screening in embryonic stem cells implicates Wnt antagonism in neural differentiation. Nat Biotechnol 20, 1240-1245, doi:10.1038/nbt763 nbt763 [pii] (2002).

[99] Kielman, M. F. et al. Apc modulates embryonic stem-cell differentiation by controlling the dosage of beta-catenin signaling. Nat Genet 32, 594-605, doi:10.1038/ng1045 ng1045 [pii] (2002).

[100] Doble, B. W., Patel, S., Wood, G. A., Kockeritz, L. K. \& Woodgett, J. R. Functional redundancy of GSK-3alpha and GSK-3beta in Wnt/beta-catenin signaling shown by using an allelic series of embryonic stem cell lines. Dev Cell 12, 957-971, doi:S1534-5807(07)00148-7 [pii] 10.1016/j.devcel.2007.04.001 (2007).

[101] Liu, Z., Scannell, D. R., Eisen, M. B. \& Tjian, R. Control of embryonic stem cell lineage commitment by core promoter factor, TAF3. Cell 146, 720-731, doi:S0092-8674(11)00881-6 [pii] 10.1016/j.cell.2011.08.005 (2011).

[102] Sun, Y., Li, H., Yang, H., Rao, M. S. \& Zhan, M. Mechanisms controlling embryonic stem cell self-renewal and differentiation. Crit Rev Eukaryot Gene Expr 16, 211-231, doi:5671614a1bbedf32,278d0bf81ca44a82 [pii] (2006).

[103] Cole, M. F., Johnstone, S. E., Newman, J. J., Kagey, M. H. \& Young, R. A. Tcf3 is an integral component of the core regulatory circuitry of embryonic stem cells. Genes Dev 22, 746-755, doi:22/6/746 [pii] 10.1101/gad.1642408 (2008).

[104] Tam, W. L. et al. T-cell factor 3 regulates embryonic stem cell pluripotency and selfrenewal by the transcriptional control of multiple lineage pathways. Stem Cells 26, 2019-2031, doi:2007-1115 [pii] 10.1634/stemcells.2007-1115 (2008).

[105] Pereira, L., Yi, F. \& Merrill, B. J. Repression of Nanog gene transcription by Tcf3 limits embryonic stem cell self-renewal. Mol Cell Biol 26, 7479-7491, doi:MCB.00368-06 [pii] 10.1128/MCB.00368-06 (2006).

[106] Santibanez, J. F., Quintanilla, M. \& Bernabeu, C. TGF-beta/TGF-beta receptor system and its role in physiological and pathological conditions. Clin Sci (Lond) 121, 233-251, doi:CS20110086 [pii] 10.1042/CS20110086 (2011).

[107] Xu, R. H. et al. NANOG is a direct target of TGFbeta/activin-mediated SMAD signaling in human ESCs. Cell Stem Cell 3, 196-206, doi:S1934-5909(08)00335-4 [pii] 10.1016/ j.stem.2008.07.001 (2008). 
[108] Wu, M. Y. \& Hill, C. S. Tgf-beta superfamily signaling in embryonic development and homeostasis. Dev Cell 16, 329-343, doi:S1534-5807(09)00086-0 [pii] 10.1016/ j.devcel.2009.02.012 (2009).

[109] Watabe, T. \& Miyazono, K. Roles of TGF-beta family signaling in stem cell renewal and differentiation. Cell Res 19, 103-115, doi:cr2008323 [pii] 10.1038/cr.2008.323 (2009).

[110] Xu, R. H. et al. BMP4 initiates human embryonic stem cell differentiation to trophoblast. Nat Biotechnol 20, 1261-1264, doi:10.1038/nbt761 nbt761 [pii] (2002).

[111] James, D., Levine, A. J., Besser, D. \& Hemmati-Brivanlou, A. TGFbeta/activin/nodal signaling is necessary for the maintenance of pluripotency in human embryonic stem cells. Development 132, 1273-1282, doi:dev.01706 [pii] 10.1242/dev.01706 (2005).

[112] Vallier, L., Reynolds, D. \& Pedersen, R. A. Nodal inhibits differentiation of human embryonic stem cells along the neuroectodermal default pathway. Dev Biol 275, 403-421, doi:S0012-1606(04)00587-1 [pii] 10.1016/j.ydbio.2004.08.031 (2004).

[113] Vallier, L., Alexander, M. \& Pedersen, R. A. Activin/Nodal and FGF pathways cooperate to maintain pluripotency of human embryonic stem cells. J Cell Sci 118, 4495-4509, doi:118/19/4495 [pii] 10.1242/jcs.02553 (2005).

[114] Ogawa, K. et al. Activin-Nodal signaling is involved in propagation of mouse embryonic stem cells. J Cell Sci 120, 55-65, doi:120/1/55 [pii] 10.1242/jcs.03296 (2007).

[115] Wilson, P. A. \& Hemmati-Brivanlou, A. Induction of epidermis and inhibition of neural fate by Bmp-4. Nature 376, 331-333, doi:10.1038/376331a0 (1995).

[116] Fei, T. et al. Genome-wide mapping of SMAD target genes reveals the role of BMP signaling in embryonic stem cell fate determination. Genome Res 20, 36-44, doi:gr. 092114.109 [pii] 10.1101/gr.092114.109 (2010).

[117] Yuasa, S. et al. Transient inhibition of BMP signaling by Noggin induces cardiomyocyte differentiation of mouse embryonic stem cells. Nat Biotechnol 23, 607-611, doi:nbt1093 [pii] 10.1038/nbt1093 (2005).

[118] Lengerke, C. et al. BMP and Wnt specify hematopoietic fate by activation of the CdxHox pathway. Cell Stem Cell 2, 72-82, doi:S1934-5909(07)00239-1 [pii] 10.1016/j.stem. 2007.10.022 (2008).

[119] Park, C. et al. A hierarchical order of factors in the generation of FLK1- and SCL-expressing hematopoietic and endothelial progenitors from embryonic stem cells. Development 131, 2749-2762, doi:10.1242/dev.01130 131/11/2749 [pii] (2004).

[120] Sadlon, T. J., Lewis, I. D. \& D'Andrea, R. J. BMP4: its role in development of the hematopoietic system and potential as a hematopoietic growth factor. Stem Cells 22, 457-474, doi:22/4/457 [pii] 10.1634/stemcells.22-4-457 (2004). 
[121] Laflamme, M. A. et al. Cardiomyocytes derived from human embryonic stem cells in pro-survival factors enhance function of infarcted rat hearts. Nat Biotechnol 25, 1015-1024, doi:nbt1327 [pii] 10.1038/nbt1327 (2007).

[122] Behfar, A. et al. Stem cell differentiation requires a paracrine pathway in the heart. FASEB J 16, 1558-1566, doi:10.1096/fj.02-0072com 16/12/1558 [pii] (2002).

[123] Zeineddine, D. et al. Oct-3/4 dose dependently regulates specification of embryonic stem cells toward a cardiac lineage and early heart development. Dev Cell 11, 535-546, doi:S1534-5807(06)00314-5 [pii] 10.1016/j.devcel.2006.07.013 (2006).

[124] Narazaki, G. et al. Directed and systematic differentiation of cardiovascular cells from mouse induced pluripotent stem cells. Circulation 118, 498-506, doi:CIRCULATIONAHA.108.769562 [pii] 10.1161/CIRCULATIONAHA.108.769562 (2008).

[125] Niwa, H., Ogawa, K., Shimosato, D. \& Adachi, K. A parallel circuit of LIF signalling pathways maintains pluripotency of mouse ES cells. Nature 460, 118-122, doi:nature08113 [pii] 10.1038/nature08113 (2009).

[126] Li, Y. et al. Murine embryonic stem cell differentiation is promoted by SOCS-3 and inhibited by the zinc finger transcription factor Klf4. Blood 105, 635-637, doi:10.1182/ blood-2004-07-2681 2004-07-2681 [pii] (2005).

[127] Cartwright, P. et al. LIF/STAT3 controls ES cell self-renewal and pluripotency by a Myc-dependent mechanism. Development 132, 885-896, doi:dev.01670 [pii] 10.1242/ dev.01670 (2005).

[128] Nichols, J., Chambers, I., Taga, T. \& Smith, A. Physiological rationale for responsiveness of mouse embryonic stem cells to gp130 cytokines. Development 128, 2333-2339 (2001).

[129] Durbin, J. E., Hackenmiller, R., Simon, M. C. \& Levy, D. E. Targeted disruption of the mouse Stat1 gene results in compromised innate immunity to viral disease. Cell 84, 443-450, doi:S0092-8674(00)81289-1 [pii] (1996).

[130] Amit, M. et al. Clonally derived human embryonic stem cell lines maintain pluripotency and proliferative potential for prolonged periods of culture. Dev Biol 227, 271-278, doi:10.1006/dbio.2000.9912 S0012-1606(00)99912-3 [pii] (2000).

[131] Xu, C. et al. Feeder-free growth of undifferentiated human embryonic stem cells. Nat Biotechnol 19, 971-974, doi:10.1038/nbt1001-971 nbt1001-971 [pii] (2001).

[132] Dvorak, P. et al. Expression and potential role of fibroblast growth factor 2 and its receptors in human embryonic stem cells. Stem Cells 23, 1200-1211, doi:2004-0303 [pii] 10.1634/stemcells.2004-0303 (2005).

[133] Li, J. et al. MEK/ERK signaling contributes to the maintenance of human embryonic stem cell self-renewal. Differentiation 75, 299-307, doi:S0301-4681(09)60124-9 [pii] 10.1111/j.1432-0436.2006.00143.x (2007). 
[134] Chazaud, C., Yamanaka, Y., Pawson, T. \& Rossant, J. Early lineage segregation between epiblast and primitive endoderm in mouse blastocysts through the Grb2MAPK pathway. Dev Cell 10, 615-624, doi:S1534-5807(06)00125-0 [pii] 10.1016/ j.devcel.2006.02.020 (2006).

[135] Buehr, M. \& Smith, A. Genesis of embryonic stem cells. Philos Trans R Soc Lond B Biol Sci 358, 1397-1402; discussion 1402, doi:10.1098/rstb.2003.1327 (2003).

[136] Kunath, T. et al. FGF stimulation of the Erk1/2 signalling cascade triggers transition of pluripotent embryonic stem cells from self-renewal to lineage commitment. Development 134, 2895-2902, doi:134/16/2895 [pii] 10.1242/dev.02880 (2007).

[137] Atkinson, S. \& Armstrong, L. Epigenetics in embryonic stem cells: regulation of pluripotency and differentiation. Cell Tissue Res 331, 23-29, doi:10.1007/s00441-007-0536-x (2008).

[138] Marks, H. et al. The transcriptional and epigenomic foundations of ground state pluripotency. Cell 149, 590-604, doi:S0092-8674(12)00409-6 [pii] 10.1016/j.cell.2012.03.026 (2012).

[139] Murchison, E. P., Partridge, J. F., Tam, O. H., Cheloufi, S. \& Hannon, G. J. Characterization of Dicer-deficient murine embryonic stem cells. Proc Natl Acad Sci U S A 102, 12135-12140, doi:0505479102 [pii] 10.1073/pnas.0505479102 (2005).

[140] Wang, Y., Medvid, R., Melton, C., Jaenisch, R. \& Blelloch, R. DGCR8 is essential for microRNA biogenesis and silencing of embryonic stem cell self-renewal. Nat Genet 39, 380-385, doi:ng1969 [pii] 10.1038/ng1969 (2007).

[141] Melton, C., Judson, R. L. \& Blelloch, R. Opposing microRNA families regulate selfrenewal in mouse embryonic stem cells. Nature 463, 621-626, doi:nature08725 [pii] 10.1038/nature08725 (2010).

[142] Xu, N., Papagiannakopoulos, T., Pan, G., Thomson, J. A. \& Kosik, K. S. MicroRNA-145 regulates OCT4, SOX2, and KLF4 and represses pluripotency in human embryonic stem cells. Cell 137, 647-658, doi:S0092-8674(09)00252-9 [pii] 10.1016/j.cell. 2009.02.038 (2009).

[143] Helland, A. et al. Deregulation of MYCN, LIN28B and LET7 in a molecular subtype of aggressive high-grade serous ovarian cancers. PLoS One 6, e18064, doi:10.1371/ journal.pone.0018064 (2011).

[144] Judson, R. L., Babiarz, J. E., Venere, M. \& Blelloch, R. Embryonic stem cell-specific microRNAs promote induced pluripotency. Nat Biotechnol 27, 459-461, doi:nbt.1535 [pii] 10.1038/nbt.1535 (2009).

[145] Thornton, J. E. \& Gregory, R. I. How does Lin28 let-7 control development and disease? Trends Cell Biol, doi:S0962-8924(12)00104-3 [pii] 10.1016/j.tcb.2012.06.001 (2012). 
[146] Subramanyam, D. et al. Multiple targets of miR-302 and miR-372 promote reprogramming of human fibroblasts to induced pluripotent stem cells. Nat Biotechnol 29, 443-448, doi:nbt.1862 [pii] 10.1038/nbt.1862 (2011).

[147] Loewer, S. et al. Large intergenic non-coding RNA-RoR modulates reprogramming of human induced pluripotent stem cells. Nat Genet 42, 1113-1117, doi:ng.710 [pii] 10.1038/ng.710 (2010).

[148] Sheik Mohamed, J., Gaughwin, P. M., Lim, B., Robson, P. \& Lipovich, L. Conserved long noncoding RNAs transcriptionally regulated by Oct4 and Nanog modulate pluripotency in mouse embryonic stem cells. RNA 16, 324-337, doi:rna.1441510 [pii] 10.1261/rna.1441510 (2010).

[149] Knezetic, J. A. \& Luse, D. S. The presence of nucleosomes on a DNA template prevents initiation by RNA polymerase II in vitro. Cell 45, 95-104, doi: 0092-8674(86)90541-6 [pii] (1986).

[150] Li, B., Carey, M. \& Workman, J. L. The role of chromatin during transcription. Cell 128, 707-719, doi:S0092-8674(07)00109-2 [pii] 10.1016/j.cell.2007.01.015 (2007).

[151] Kagey, M. H. et al. Mediator and cohesin connect gene expression and chromatin architecture. Nature 467, 430-435, doi:nature09380 [pii] 10.1038/nature09380 (2010).

[152] Leeb, M. et al. Polycomb complexes act redundantly to repress genomic repeats and genes. Genes Dev 24, 265-276, doi:24/3/265 [pii] 10.1101/gad.544410 (2010).

[153] Bilodeau, S., Kagey, M. H., Frampton, G. M., Rahl, P. B. \& Young, R. A. SetDB1 contributes to repression of genes encoding developmental regulators and maintenance of ES cell state. Genes Dev 23, 2484-2489, doi:23/21/2484 [pii] 10.1101/gad.1837309 (2009).

[154] Fazzio, T. G., Huff, J. T. \& Panning, B. An RNAi screen of chromatin proteins identifies Tip60-p400 as a regulator of embryonic stem cell identity. Cell 134, 162-174, doi:S0092-8674(08)00692-2 [pii] 10.1016/j.cell.2008.05.031 (2008).

[155] Stielow, B. et al. Identification of SUMO-dependent chromatin-associated transcriptional repression components by a genome-wide RNAi screen. Mol Cell 29, 742-754, doi:S1097-2765(08)00164-0 [pii] 10.1016/j.molcel.2007.12.032 (2008).

[156] Yuan, P. et al. Eset partners with Oct4 to restrict extraembryonic trophoblast lineage potential in embryonic stem cells. Genes Dev 23, 2507-2520, doi:23/21/2507 [pii] 10.1101/gad.1831909 (2009). 